\title{
Experimental Study on the Catalytic Reduction of NOx by Fe and Ce During the Coke Combustion Process
}

\author{
Qi Wang ${ }^{1,2}$, SongYang ${ }^{2,3}$, Shoujun Liu ${ }^{2,3}$, Lili Chen ${ }^{1,2}$, Tingting Jiao ${ }^{1,2}$ and Ju Shangguan ${ }^{1,2, *}$ \\ ${ }^{1}$ State Key Laboratory of Clean and Efficient Coal Utilization, Taiyuan University of Technology, Taiyuan 030024, Shanxi, China \\ ${ }^{2}$ Shanxi Engineering Center of Civil Clean Fuel, Taiyuan University of Technology, Taiyuan 030024, Shanxi, China \\ ${ }^{3}$ College of Chemistry and Chemical Engineering, Taiyuan University of Technology, Taiyuan 030024, Shanxi, China
}

\begin{abstract}
NO}_{\mathrm{x}}$ emissions during the combustion of coal would cause serious pollution to the atmosphere. It is particularly important to reduce $\mathrm{NO}_{x}$ pollution during the combustion process by replacing loose coal with clean coke. The use of clean coke for civil is one of the main ways to reduce $\mathrm{NO}_{\mathrm{x}}$ emissions, which is mainly formed by the mixed dry distillation of metal additives and coal. The coke samples with different proportions of metal additives were prepared by physical mixing method, and the $\mathrm{NO}$ emission law of clean coke at different temperatures was studied in a high-temperature tube furnace reactor. The results show that the addition of $\mathrm{Fe}$ alone has a significant effect on the control of $\mathrm{NO}_{\mathrm{x}}$ emissions, and the co-doping with $\mathrm{Ce}$ can further promote the reduction of $\mathrm{NOx}$, so as to achieve the final low emission of $\mathrm{NO}_{\mathrm{x}}$. While the reaction temperature is $1000{ }^{\circ} \mathrm{C}$ and the addition ratio is $2: 1$, the $\mathrm{NOx}$ reduction rate is $73 \%$. It has important practical value and scientific significance for the clean utilization of coal and the treatment of NOx in the atmosphere.
\end{abstract}

\section{Introduction}

As a primary energy source, direct combustion of coal is the main way of utilization. However, the contribution of coal combustion to the emission of $\mathrm{NO}_{\mathrm{X}}$ pollutants is huge ${ }^{[1]}$. The emitted $\mathrm{NO}_{\mathrm{X}}$ can form acid rain, photochemical smog, also cause the greenhouse effect ${ }^{[2,3]}$, and ultimately endanger human health. Therefore, it is imperative to control $\mathrm{NO}_{\mathrm{X}}$ emissions during coal combustion. But the combustion of pulverized coal is very complicated, and the combustion of coke is the most influential link, therefore. Many studies have focused on the coke combustion stage ${ }^{[4]}$. Transition metal oxides also show excellent catalytic performance and can effectively promote the migration of fuel nitrogen to the gas phase ${ }^{[5]}$. Therefore, it can be boldly guessed that the metal additives also have a catalytic effect on the control of $\mathrm{NO}_{\mathrm{X}}$ emissions during the combustion process. Zhao et al. ${ }^{[6]}$ found that both $\mathrm{Na}$ and $\mathrm{Fe}$ loading reduced $\mathrm{NO}_{\mathrm{X}}$ emissions during coke combustion. Zhong et al. ${ }^{[7]}$ believed that iron can effectively catalyse the reduction of $\mathrm{NO}_{\mathrm{X}}$ during the process of high temperature combustion of coal char and significantly reduce $\mathrm{NO}_{\mathrm{X}}$ emissions. Literature ${ }^{[8]}$ believed that different metals have different catalytic activity factors, and the catalytic activity of iron depends on temperature. Ce can change the reducibility of the catalyst surface to improve the catalytic activity. Current research is still focused on the effect of single-metal additives on combustion denitrification, and there is a lack of research on the combined effect of composite

metal additives on the combustion process. Therefore, this work has studied the effect of transition metals and rare earth metals in the combustion of co-catalysis $\mathrm{NO}_{\mathrm{X}}$ reduction, and obtained the corresponding laws.

\section{Materials and Methods}

\subsection{Coal sample modification}

Select coking coal as the experimental sample. Firstly, because of the complex mineral composition of coal, in order to simplify the research, the demineralized coal was selected as the research object. In this paper, $\mathrm{HCl}-\mathrm{HF}$ acid pickling was used to remove minerals, soak in a water bath at $60{ }^{\circ} \mathrm{C}$ for 4 hours, and rinse with deionized water until $\mathrm{Cl}^{-}$is not detected, and demineralized coal is prepared. Next the coal was baked in an oven at $105^{\circ} \mathrm{C}$ for about 6 hours. Then it is crushed and sieved to select a coal sample with a particle size of about $0.2 \mathrm{~mm}$. Afterwards, $1 \%, 2 \%$, $3 \%$ and $4 \% \mathrm{Fe}$ additives were loaded on the demineralized coal using a physical mixing method. Make the Fe additives and demineralized coal as homogeneous as possible.

\subsection{Coke preparation}

The pyrolysis was completed in a high-temperature tube furnace, the sample was heated at a rate of $10{ }^{\circ} \mathrm{C} / \mathrm{min}$ to $1000{ }^{\circ} \mathrm{C}$, and was subjected to high-temperature pyrolysis in an $\mathrm{Ar}$ atmosphere of $50 \mathrm{~mL} / \mathrm{min}$ for $1 \mathrm{~h}$, and then naturally cooled to room temperature. Finally, the coke is sieved to $40 \sim 80$ mesh. The industrial analysis and

*Corresponding author: shanggj62@163.com 
elemental analysis of raw coal char (RC) and demineralized coal char (DC) are shown in Table 1. The nitrogen content of demineralized coke is higher than that of coke. This may because the minerals in coal promote the migration and emission of nitrogen-containing substances to gas during coal pyrolysis.

Table 1. The proximate analysis and ultimate analysis of raw char (RC) and demineralized char (DC)

\begin{tabular}{cccccccccc}
\hline & \multicolumn{4}{c}{ Proximate analysis $(w t \%)$} & \multicolumn{5}{c}{ Ultimate analysis $(w t \%)$} \\
\cline { 2 - 9 } & $\mathrm{M}_{\mathrm{ad}}$ & $\mathrm{A}_{\mathrm{d}}$ & $\mathrm{V}_{\mathrm{daf}}$ & $\mathrm{FC}_{\mathrm{ad}}$ & $\mathrm{C}_{\mathrm{daf}}$ & $\mathrm{O}_{\text {daf }}$ & $\mathrm{H}_{\text {daf }}$ & $\mathrm{N}_{\text {daf }}$ & $\mathrm{S}_{\text {daf }}$ \\
\hline $\mathrm{YC}$ & 0.15 & 9.99 & 1.78 & 88.08 & 79.09 & 19.12 & 0.23 & 1.16 & 0.40 \\
$\mathrm{DC}$ & 0.20 & 0.49 & 1.69 & 95.72 & 89.45 & 8.77 & 0.20 & 1.26 & 0.32 \\
\hline
\end{tabular}

\subsection{Experimental process}

The combustion experiment was carried out in a tube furnace. Before each reaction, weigh about $0.5 \mathrm{~g}$ of the coke, and place it in the middle constant temperature zone of the reaction tube, The Ar gas is flowed at a flow rate of $50 \mathrm{~mL} / \mathrm{min}$, and purge for 5 minutes to purge the air in the pipe, heat up to the combustion temperature required for the experiment, after the constant temperature is stable for 10 minutes, switch the $\mathrm{O}_{2} / \mathrm{Ar}$ mixture, adjust the flow rate to $200 \mathrm{~mL} / \mathrm{min}$, and the tail gas end is connected to a flue gas analyzer (KANE9506) for online detection of $\mathrm{NO}_{\mathrm{X}}$. After the experiment is completed, coal ash is collected, and XRD is used to characterize the crystal form of additives in the ash sample. Each experiment was repeated twice, and when the error of parallel experiment data was less than $2 \%$, the average value was taken.

The amount of $\mathrm{NO}_{\mathrm{X}}$ produced and the decrease ratio are shown in formulas (1) and (2).

$$
m_{N O_{X}}=Q \times 10^{-6} \int_{0}^{t} C_{N O_{X}}(t) d t
$$

$m_{N O_{X}}$ - the amount of $\mathrm{NO}_{\mathrm{X}}$ produced by coke combustion, $\mathrm{mg}$

$Q$ - the volume flow of air, $\mathrm{mL} / \mathrm{min}$

$C_{N O_{X}}$ - the mass concentration of $\mathrm{NO}_{\mathrm{X}}$ in flue gas at time $\mathrm{t}, \mathrm{mg} / \mathrm{m}^{3}$

$$
\varphi=\frac{W_{N O_{X}(\text { coke }-0)}-W_{N O_{X}(\text { coke }-1)}}{W_{N O_{X}(\text { coke }-0)}}
$$

$\varphi$ - the reduction ratio of $\mathrm{NO}_{\mathrm{X}}$ of clean coke, $\%$

$W_{N O_{X}(\text { coke- } 0)}$ - the amount of $\mathrm{NO}_{\mathrm{X}}$ produced during the combustion of coke, $\mathrm{mg}$

$W_{N O_{X}(\text { coke-1) }}$ - the amount of $\mathrm{NO}_{\mathrm{X}}$ produced during the combustion of clean coke, $\mathrm{mg}$

\section{Results \& Discussion}

\subsection{Effect of iron loading ratio on NOx emissions from demineralized coke combustion}

When the demineralized coke with different iron loading ratios is burned separately, the NOx emission and decrease ratio are shown in Figure 1 and Figure 2, respectively. It can be seen from the Figure 1 that NOX emissions are negatively correlated with the temperature range, that is, as the temperature increases, the emissions decrease. It shows that increasing the temperature is beneficial to reduce NOX emissions. However, the higher the load, the better NOX reduction. When the load ratio exceeds $4 \%$, the NOX emissions will be higher than $3 \%$ at the same temperature. And it can be seen from that the best temperature is $900{ }^{\circ} \mathrm{C}$, the emission of NOx of was calculated to be $1.18 \mathrm{mg}$.

In order to express the decrease of NOX by loading additives more vividly, compare the release of NOX in various proportions with the demineralized coke without additives. The decrease ratio at each temperature is shown in Figure 2. The calculation can be obtained at $900{ }^{\circ} \mathrm{C}, 3 \%$ with the addition of $\mathrm{Fe}$ additives, the $\mathrm{NO}_{\mathrm{X}}$ emission is $1.18 \mathrm{mg}$, and the $\mathrm{NO}_{\mathrm{X}}$ decrease rate is $60.5 \%$. Under these conditions, the $\mathrm{NO}_{\mathrm{X}}$ emission is the least. It can be inferred that a $3 \%$ Fe load has the best effect on catalytic reduction of $\mathrm{NO}_{\mathrm{X}}$ release. Therefore, in this experiment, clean coke with a load of $3 \% \mathrm{Fe}_{2} \mathrm{O}_{3}$ co-pyrolysis releases the least amount of NOx, which proves that this load of additives is most conducive to reducing the release of $\mathrm{NO}_{\mathrm{X}}$. Meanwhile, the catalytic effect of $\mathrm{Fe}$ in the NO-coke reaction is proved ${ }^{[9]}$, that is, the addition of $\mathrm{Fe}_{2} \mathrm{O}_{3}$ is beneficial to promote the reduction of $\mathrm{NO}_{\mathrm{X}}$, thereby reducing the release of $\mathrm{NO}_{\mathrm{X}}$.

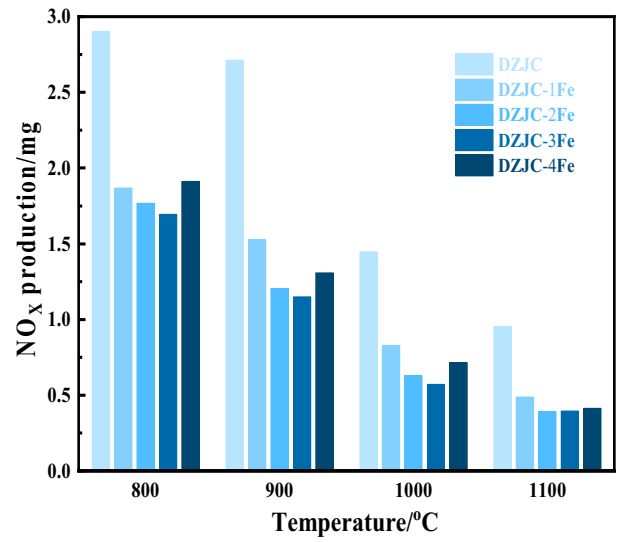

Figure 1. NOx production with different iron loading ratio 


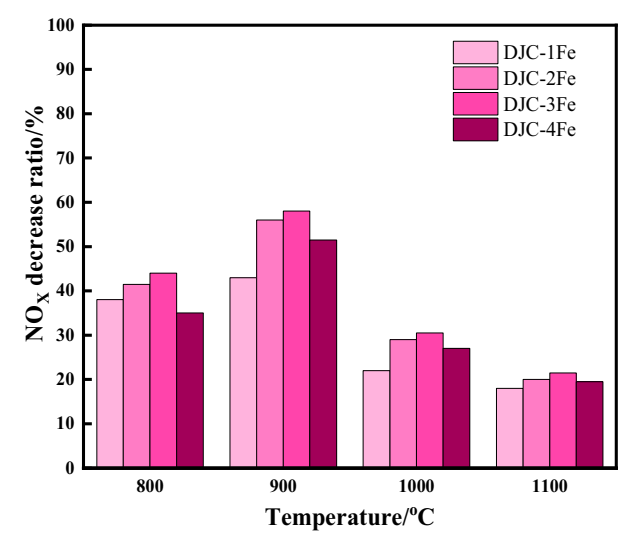

Figure 2. $\mathrm{NO}_{\mathrm{X}}$ decrease ratio with different iron loading ratios

\subsection{Effect of Fe-Ce composite ratio on NOx emissions from demineralized coke combustion}

The $\mathrm{NO}_{\mathrm{x}}$ emissions and decrease ratio during the combustion process with different $\mathrm{Fe}-\mathrm{Ce}$ composite ratios are shown in Figure 3 and Figure 4, respectively.

It can be seen from the figure that the effect of single additive $\mathrm{CeO}_{2}$ loading is far less than that of single $\mathrm{Fe}_{2} \mathrm{O}_{3}$ loading. Compared with $\mathrm{DC}-3 \mathrm{Fe}$ and $\mathrm{DC}-3 \mathrm{Ce}$, the $\mathrm{NO}_{\mathrm{X}}$ emission of coke combustion under the composite auxiliary is reduced However, when the two metals are combined loading, the release of $\mathrm{NO}_{\mathrm{X}}$ at $\left(800-1100{ }^{\circ} \mathrm{C}\right)$ is effectively reduced. When the recombination ratio is less than 2, the $\mathrm{NO}_{\mathrm{X}}$ reduction rate increases with the increase of $\mathrm{CeO}_{2}$ load, but a downward trend appears when the temperature rises to $1100{ }^{\circ} \mathrm{C}$. When the $\mathrm{CeO}_{2}$ to $\mathrm{Fe}_{2} \mathrm{O}_{3}$ load ratio exceeds 2 , the reduction of $\mathrm{NO}_{\mathrm{x}}$ is directly related to the temperature, and this trend is proportional to temperature. The reduction of $\mathrm{NO}_{\mathrm{x}}$ emissions from coke combustion after the composite addition of $\mathrm{Fe}$ and $\mathrm{Ce}$ oxide additives is more obvious, and the $\mathrm{NO}_{\mathrm{x}}$ reduction rate of DJC-2FeCe is the highest, and the effect is the most significant. Therefore, the experimental results show that the doping of cerium is not always beneficial, and a small amount of doping of cerium is beneficial to further reduce combustion $\mathrm{NO}_{\mathrm{X}}$ release on the basis of supporting ironbased additives.

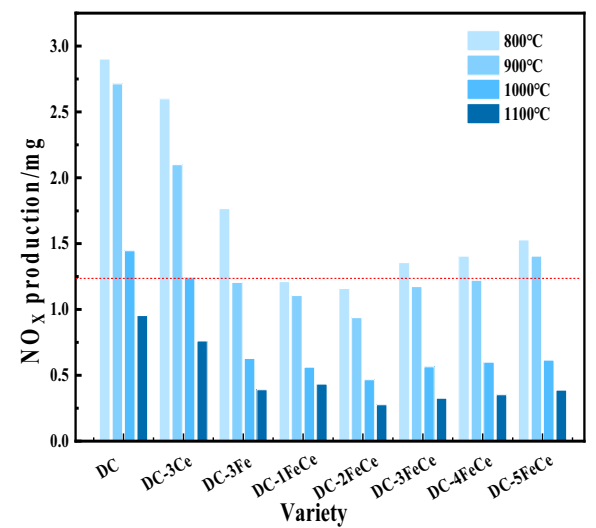

Figure 3. NOx production with different iron loading ratios

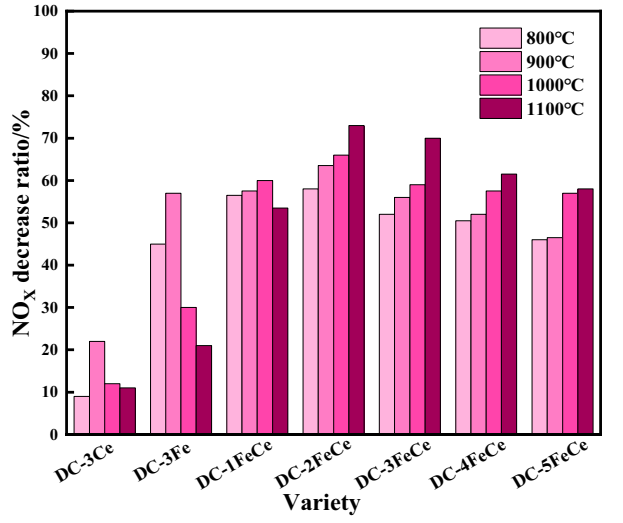

Figure 4. $\mathrm{NO}_{\mathrm{x}}$ decrease ratio with different iron loading ratios

\subsection{Effect of temperature on NOx emissions during the combustion of demineralized coke with the optimum ratio of $\mathrm{Fe}-\mathrm{Ce}$}

The $\mathrm{NO}_{\mathrm{x}}$ emissions and decrease ratio during the combustion process of demineralized coke with $\mathrm{Fe}-\mathrm{Ce}$ composite ratio of 2:1 are shown in Figure 5.

Obviously, during the combustion process, the $\mathrm{NO}_{\mathrm{X}}$ emissions of demineralized coke with the optimal load ratio gradually decreases, which corresponds to a linear increase in the $\mathrm{NO}_{\mathrm{X}}$ reduction rate. This shows that temperature is a key factor affecting combustion, and high temperature can significantly reduce $\mathrm{NO}_{\mathrm{X}}$ emissions during combustion. When the combustion temperature increases to $1100{ }^{\circ} \mathrm{C}$, the amount of $\mathrm{NO}_{\mathrm{X}}$ emitted by the coke is $0.28 \mathrm{mg}$, and $\mathrm{NO}_{\mathrm{X}}$ reaches $73 \%$. This indicates that high temperature is beneficial to reduce the release of $\mathrm{NO}_{\mathrm{X}}$ in coke. The literature ${ }^{[10]}$ believes that as the high temperature time passes, the coke enters the burn-out stage, and the $\mathrm{O}$ concentration decreases. At this time, although the coke $\mathrm{NO}_{\mathrm{X}}$ is continuously formed, it decomposes quickly at the same time, and part of the $\mathrm{NO}_{\mathrm{X}}$ that has been generated is reduced by metal decomposed into $\mathrm{N}$ or $\mathrm{N}_{2}$, Ce doping improves the reducibility of mixed oxides, resulting in a reduction in overall $\mathrm{NO}_{\mathrm{x}}$ emissions.

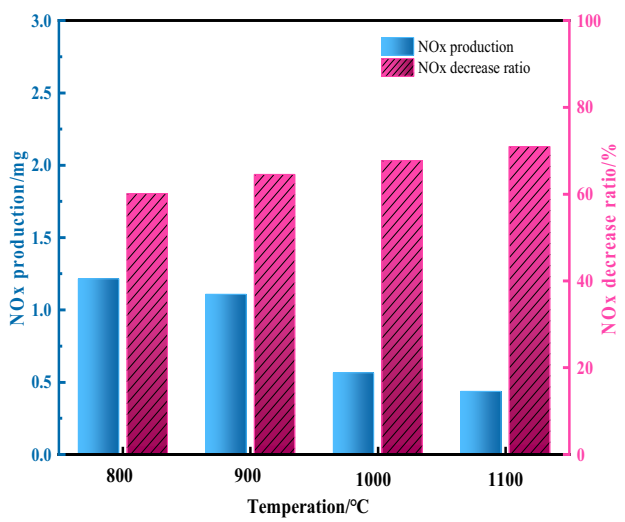

Figure 5. $\mathrm{NO}$ x production and decrease ratio with $2 \mathrm{FeCe}$ 


\subsection{Phase morphology analysis of loading additives before and after coke combustion}

The XRD analysis of the auxiliary agent in the demineralized coke and in the ash after combustion are shown in Figure 6 and Figure 7, respectively.

As shown in the Figure 6, XRD characterization analysis was carried out on the coke to determine the phase morphology of the auxiliary agent, the coke doped with $\mathrm{Fe}$ has obvious $\mathrm{Fe}_{2} \mathrm{O}_{3}$ and $\mathrm{Fe}$ diffraction peaks, and the intensity of the diffraction peaks is strong, which may be the reason for the low catalytic efficiency of crystalline iron oxide. After the co-doping of $\mathrm{Ce}$, the peak strength of iron diffraction peak of each load auxiliary sample is still gradually weakening, which shows that the addition of $\mathrm{Ce}$ can effectively change the crystallinity of iron. Researches have shown ${ }^{[11]}$ that when metal oxides interact, cerium oxide can promote the storage and release of oxygen improves the mobility of oxygen and forms surface and structural oxygen vacancies, thereby improving the redox properties of the catalyst ${ }^{[12]}$.

In order to clarify the phase morphology of the composite additives after combustion, the burned ash was subjected to XRD characterization, the result is shown in Figure 7. Through the analysis of the ash content, it is found that the burned ash contains almost no other components, except for the added compound additives. Only the phase structures of iron and cerium are obtained by the characterization, and they are in their respective oxide forms after combustion, namely $\mathrm{Fe}_{2} \mathrm{O}_{3}, \mathrm{CeO}_{2}$, and there are almost no elemental Fe compounds in the phase. This is related to the combustion reaction is a strong oxidizing system, and the composite assistant as a catalyst is finally oxidized under this oxidizing condition.

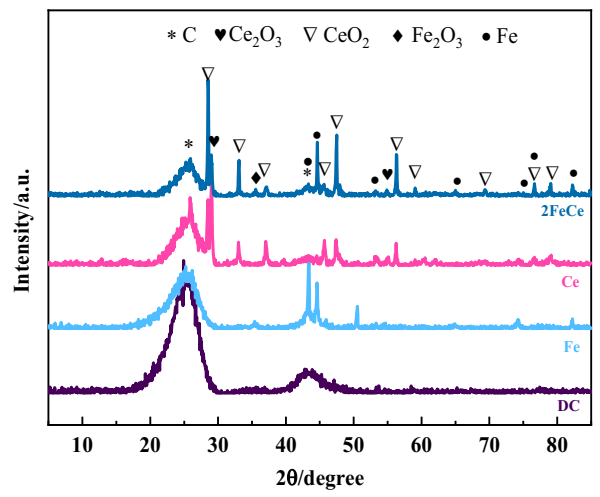

Figure 6. Fe-Ce phase transition law before combustion

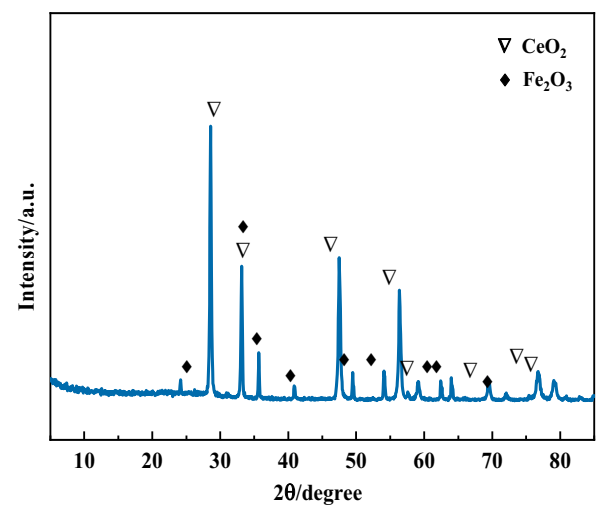

Figure 7. Fe-Ce phase transition law after combustion

\section{Conclusions}

The effect of composite metal promoters in the catalytic reduction of $\mathrm{NO}_{\mathrm{x}}$ was studied in a high-temperature tubular furnace reactor. The results are as follows: In the combustion process of demineralized coke, the addition of metal additives can not only inhibit the production of $\mathrm{NO}_{\mathrm{X}}$, but also reduce the release of $\mathrm{NO}_{\mathrm{X}}$, and ultimately achieve lower $\mathrm{NO}_{\mathrm{x}}$ emissions. During the combustion of coke, the catalytic effect of $\mathrm{Fe}-\mathrm{Ce}$ composite is greater than that of iron or cerium alone. While the reaction temperature is $1000{ }^{\circ} \mathrm{C}$ and the addition ratio is $2: 1$, the catalytic effect on $\mathrm{NO}_{\mathrm{x}}$ decrease ratio is optimal, the $\mathrm{NO}_{\mathrm{x}}$ emissions is $0.28 \mathrm{mg}$, and the $\mathrm{NO}_{\mathrm{X}}$ decrease ratio is $73 \%$, which indicate that the modification by a proper amount of $\mathrm{Ce}$ doping is beneficial to further improve the effect of iron additives. The composite addition method can effectively reduce $\mathrm{NO}_{\mathrm{x}}$ emissions and control air pollutants, which has important practical significance for achieving clean and efficient utilization of coal.

\section{Acknowledgments}

This work was supported by National Natural Science Foundation of China (21878210), Shanxi "1331" Civil Clean Fuel Engineering Research Center, Scientific and Technological Innovation Programs of Higher Education Institutions in Shanxi (2019L0313), Patent Promotion and implementation in Shanxi Province (20200719) and sponsored by Taiyuan Green Coke Energy Co., Ltd. (China).

\section{References}

1. H. Ma, L. Zhou, S. Ma, Z. Wang, H. Du, J. Li, W. Zhang and P. Guo. J. Energy, 32, 1464-1473(2018)

2. W. Fan, Y. Li, Q Guo, C. Chen and Y. Wang. J. Energy, 125, 417-426(2017)

3. X. Liu, Z. Luo and C. Yu, Fuel, 242, 389-397(2019)

4. J. Xu, R. Sun, T.M. Ismail, S. Sun and Z. Wang. Energy Fuel, 31, 7502-7509(2017)

5. J. Cheng, F. Zhou, X. Xuan, J. Liu, J. Zhou and K. Cen. Fuel, 181, 820-826(2016) 
6. Z. Zhao, W. Lia, J. Qiu and B. Li. Fuel, 81, 23432348(2002)

7. B. Zhong and H. Tang. Int. J. Chem. React. Eng, 6, (2011)

8. P. Li, Y. Xin, Q. Li, Z. Wang, Z. Zhang and L. Zheng. Environ. Sci. Technol, 46, 9600-9605(2012)

9. Z. Lei, J. Yan, J. Fang, H. Shui, S. Ren, Z. Wang, Z. Li, Y. Kong and S. Kang. Energy, 216, (2021)

10. R. Brackmann, C. Alves, B. Woyames, F.S. Toniolo and M Schmal. Appl. Catal. A: Gen, 600, (2020)

11. B. Gradoń and J. Lasek. Fuel, 89, 3505-3509(2010)

12. H. Chen, A. Sayari and A. Adnot. Appl. Catal. B, 32, 195-204(2001) 